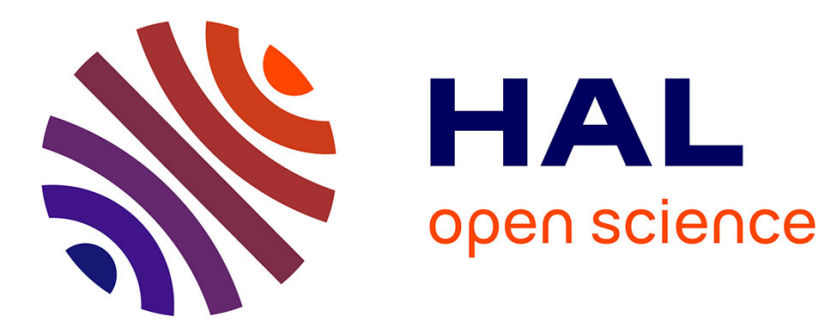

\title{
The effects of brood ester pheromone on foraging behaviour and colony growth in apicultural settings
}

Marianne Peso, Andrew Barron

\section{To cite this version:}

Marianne Peso, Andrew Barron. The effects of brood ester pheromone on foraging behaviour and colony growth in apicultural settings. Apidologie, 2014, 45 (5), pp.529-536. 10.1007/s13592-0140270-9 . hal-01234750

\author{
HAL Id: hal-01234750 \\ https://hal.science/hal-01234750
}

Submitted on 27 Nov 2015

HAL is a multi-disciplinary open access archive for the deposit and dissemination of scientific research documents, whether they are published or not. The documents may come from teaching and research institutions in France or abroad, or from public or private research centers.
L'archive ouverte pluridisciplinaire HAL, est destinée au dépôt et à la diffusion de documents scientifiques de niveau recherche, publiés ou non, émanant des établissements d'enseignement et de recherche français ou étrangers, des laboratoires publics ou privés. 


\title{
The effects of brood ester pheromone on foraging behaviour and colony growth in apicultural settings
}

\author{
Marianne Peso, Andrew B. BArron \\ Department of Biological Sciences, Macquarie University, Sydney, NSW 2109, Australia \\ Received 20 August 2013 - Revised 14 December 2013 - Accepted 8 January 2014
}

\begin{abstract}
Brood ester pheromone (BEP) is a pheromone emitted by developing larvae in a honey bee (Apis mellifera) colony. It has been shown to have multiple potential commercially beneficial effects on worker physiology and behaviour, but like other bee pheromones, its effects are likely context dependent. To better understand the utility of BEP treatment, we examined the effects of BEP treatment in an apicultural setting (using a SuperBoost BEP treatment) in two contexts: in newly established colonies from bee packages in the summer and on large, established colonies in the autumn. We found that in small, newly established colonies, BEP treatment had no effect on colony growth (measured as brood cover). Further, BEP treatment decreased overall foraging activity and the proportion of pollen foragers. In established colonies, BEP had no effect on brood cover or foraging behaviour later in the season. Our data show that BEP treatments can change the behaviour of bees, but these can only translate into improved colony conditions if other factors are not limiting of colony performance.
\end{abstract}

\section{Apis mellifera / brood ester pheromone / colony growth / foraging}

\section{INTRODUCTION}

Brood ester pheromone (BEP) is a pheromone emitted by developing larvae in the honey bee (Apis mellifera) colony. BEP has been chemically characterised and contains 10 methyl and ethyl fatty acid esters (Le Conte et al. 1990). It has been shown to have multiple effects on worker physiology and behaviour, many of which could translate into commercial benefits for beekeepers. Consequently, there has been a great deal of interest in the sociobiological effects of BEP and its possible commercial application (Sagili and Pankiw 2009; Sagili et al. 2011; Lait et al. 2012; Sagili and Breece 2012).

Corresponding author: M. Peso, marianne.peso@mq.edu.au

Manuscript editor: Stan Schneider
Adding synthetic BEP to colonies has been shown to affect worker bee physiology by inhibiting worker ovary activation (Arnold et al. 1994; Mohammedi et al. 1998) and altering protein levels in brood-food-producing glands (Peters et al. 2010). BEP affects worker behaviour by increasing the activity of existing foragers, particularly pollen foragers (Pankiw et al. 1998; Pankiw and Page 2001; Pankiw 2007; Pankiw et al. 2008; Sagili and Pankiw 2009; Sagili et al. 2011). It increases brood rearing (Pankiw et al. 2004; Sagili et al. 2011) and stimulates the capping of cells containing mature larvae (Le Conte et al. 1990).

Most studies concerning BEP function were necessarily performed in a controlled setting using small experimental colony units replicated in size and condition. In these experiments, BEP was applied daily on glass slides (Barron et al. 2002; Pankiw et al. 2004; Sagili and Pankiw 2009; Peters et al. 2010; Sagili et al. 2011) or dissolved 
in bee candy (Arnold et al. 1994; Le Conte et al. 2001) and applied for a fixed, and sometimes brief, amount of time. These studies have yielded our understanding of the basic semiochemistry of BEP, which suggested important potential apicultural applications of BEP to manage bee behaviour to a commercial benefit. However, daily application of BEP is not practical under commercial apiary conditions. To resolve this, a slowrelease system has been developed for the longterm administration of BEP to commercial bee colonies (Pankiw et al. 2011). SuperBoost (SB) (ConTech, Delta, BC, Canada) releases BEP through a porous membrane when contacted by worker bees (Moeri et al. 2011; Lait et al. 2012; Sagili and Breece 2012). Each application is expected to deliver BEP at biologically relevant concentrations for up to 5 weeks (Lait et al. 2012).

Worker responses to BEP are highly dependent on the social context and the colony condition. For example, when exposed to BEP, forager bees can increase their level of foraging activity (but not always, see Pankiw 2004), or may change their foraging specialisation (Pankiw et al. 1998; Pankiw et al. 2004; Pankiw 2007; Pankiw et al. 2011), while nurse bees increase their nursing capability (but only in combination with a queen mandibular pheromone) (Peters et al. 2010). Furthermore, BEP has complex effects on the behavioural development of bees, in some cases accelerating and in others delaying the onset of foraging (Le Conte et al. 2001). The social environment of a small controlled experimental colony is not the same as a larger standard apiculturally managed colony, and because social factors can influence how bees respond to BEP, it is not clear which effects of BEP supplementation are most likely to be seen in an apicultural setting.

To date, three studies have examined the effects of BEP supplementation using SB applied under representative apicultural conditions. Two of the studies were conducted on established colonies (Moeri et al. 2011; Sagili and Breece 2012) and one on colonies that were newly established from packages (Lait et al. 2012). Thus far, results have varied between studies. In established colonies, BEP treatment resulted in increased brood production (Moeri et al. 2011; Sagili and Breece 2012). In new colonies, BEP supplementation significantly increased honey production, but while a trend to higher brood production was seen, this was not statistically significant (Lait et al. 2012).

Our objective here was to further analyse the effects of BEP supplementation with SB in both new and established colonies and carefully examine the impacts of BEP treatment on both foraging behaviour and colony growth. Detailing how individual bees reacted to the treatment would help us comprehend colonylevel responses to the treatment and may clarify why the reported effects of BEP have varied.

We examined the effects of BEP on colony growth and foraging in two contrasting, but apiculturally relevant, contexts. First, we examined the effects of BEP in newly established colonies from 'bee packages' (as in Lait et al. 2012). These are commercially available boxes containing one queen and $2.26 \mathrm{~kg}$ of worker bees that have been shaken off frames from a strong colony when the foraging force is away, resulting in a package of relatively young bees (Naumann and Winston 1990). It is a common practice for beekeepers to establish new colonies from packages in the spring when developing a new apiary. Given the results presented in Lait et al. (2012), we did not expect treatment to increase brood production significantly in this experiment. We did expect that treatment with BEP would increase foraging in these colonies, as BEP treatment has increased overall foraging activity and pollen foraging in a number of studies in small experimental colonies (Barron et al. 2002; Pankiw 2004) and in commercial colonies (Pankiw et al. 2011; Lait et al. 2012).

Second, in autumn we examined established colonies occupying two 8-frame Langstroth boxes that had completed several brood cycles throughout the summer. These colonies had a demographic profile typical of managed commercial bee hives and varying amounts of brood (from 0.8 to 3.85 frames of capped brood). Under these conditions, we expected that colonies treated with BEP would experience increased growth (Moeri et al. 2011; Sagili et al. 2011) and increased overall and pollen foraging consistent with tests of 
BEP in more controlled colony situations (Pankiw et al. 1998; Pankiw 2004; Sagili et al. 2011).

\section{METHODS}

\subsection{Experiment 1: effects of brood ester pheromone in newly established hives}

\subsubsection{Colony establishment}

This experiment was conducted in a commercial apiary (Austrapi Pty Ltd.) in Oberon, NSW, Australia, in the early summer of 2009. Eighty colonies from the 100colony apiary were randomly selected for brood cover analysis. These colonies were established from commercial packages on December 21 (early summer in Australia) in single-level eight-frame Langstroth hives containing empty drawn comb free of honey, brood and pollen. Forty of the colonies were treated with SB attached to frames in the centre of the hive box (usually where a brood is found, but these colonies were broodless) according to ConTech instructions, while the other 40 control colonies were left untreated. The BEP blend in SB contains (percent by mass) $2.11 \%$ methyl palmitate, $4.19 \%$ ethyl palmitate, $17.3 \%$ methyl stearate, $8.04 \%$ ethyl stearate, $21.66 \%$ methyl oleate, $7.5 \%$ ethyl oleate, $3.82 \%$ ethyl linoleate, $16.53 \%$ methyl linolenate and $10.77 \%$ ethyl linolenate. The SB membrane is estimated to release $1.6 \mathrm{mg}$ of pheromone per day (approximately 2,417 larval equivalents) (Borden 2011). SB releases synthetic BEP for 5 weeks (Borden 2011).

\subsubsection{Evaluation of brood cover in the hive}

To examine the effect of BEP treatment on colony growth, we photographed the experimental colony frames with capped brood 3 and 5 weeks after pheromone treatment. If the queen started laying eggs right at colony establishment, after 3 weeks she would have completed her first brood cycle. By photographing at this time point, we were capturing her first laid brood while in the pupal stage and covered with an obvious wax cap and thus easy to score. We photographed the frames again at 5 weeks to observe any potential changes in brood cover over the total period of SB function (Borden 2011).

In order to quantify the amount of capped brood on each colony, we estimated the amount of capped brood cover (accurate to $10 \%$ ), from the photographs for both sides of each frame in the colony. We added these values together to produce a single value - the number of frames covered with capped brood for each hive. To validate the estimation method, ImageJ software was used to scale the photos, and the brood area was calculated in centimetres squared by enclosing the brood area with an outlining tool. Three independent observers conducted ImageJ measurements of the capped brood. We conducted a correlation between the brood area estimates (converted to centimetres squared) to the ImageJ measures. Since the estimated values were highly correlated with the ImageJ values (Pearson correlation; $r=0.871, P<0.0001, N=29)$, we employed the estimation method for this study.

\subsubsection{Foraging observations}

Of the 80 experimental hives in this experiment, 16 were selected randomly (using a random number table) for foraging observations. Two observers recorded data for eight replicate colonies of the two experimental treatments. A single BEP-treated colony was removed from the analysis due to queen death early in the experiment, leaving 15 colonies for behavioural analysis.

Behavioural observations were conducted from January 10 to January 18 , 2010. Each hive entrance was observed for $20 \mathrm{~min}$ per day, split into two 5-min periods in the morning (09:00-12:00) and two 5-min periods in the afternoon (13:00-16:00) with at least 75 min between observations. Observers covered the hive entrance with a metal mesh leaving only a narrow opening so the returning foragers were easier to see. The number of pollen foragers (easily distinguished by the pollen balls on their corbiculae) and non-pollen foragers entering the hive were recorded during each observation period.

\subsection{Experiment 2: effects of supplemental brood ester pheromone on workers in established hives}

\subsubsection{Colony establishment}

Two weeks prior to this experiment, 100 (different) standard commercial colonies (two-level Langstroth 
eight-frame hives) were moved to a field in Burraga, NSW, Australia (50-km southeast of Oberon). The queen was confined to the bottom level of the hive with a queen excluder mesh; ensuring brood production was confined to the lower level of the hive. On March 16, 2010 (early autumn), we randomly selected 60 colonies from this 100-colony commercial apiary; half were treated with $\mathrm{SB}$ on one of the centre frames as in experiment 1 , while half were left untreated.

\subsubsection{Evaluation of brood cover in established hives}

We photographed the frames containing capped brood in 60 hives (30 treated with BEP and 30 without) on the day we put in the pheromone treatment and again after 3 weeks. We started the experiment colonies with varying amounts of brood in order to test the effects of BEP treatment with SB under conditions that beekeepers would regularly experience. To account for varying colony size, we did two different things: (1) measured a large number of colonies and (2) measured the total amount of brood in each colony (as in experiment 1) as well as the difference in brood cover from before and after 3 weeks of treatment, therefore addressing absolute brood area as well as change in brood area over the course of the experiment. We did not need to do this for colonies in experiment 1 , as there was no brood present at the start of that experiment.

\subsubsection{Behavioural observations}

Fourteen colonies were randomly selected from the 60 colonies used in this experiment for behavioural observation (with a random number table): seven with BEP treatment and seven without. Observations on the number of pollen and nonpollen foragers were conducted using the same protocol as in experiment 1 from March 26 to April 4, 2010.

\subsubsection{Statistical analysis}

For both experiments, differences in brood cover between treatments were checked for normality and analysed using $t$ tests. For experiment 1, differences in total number of foragers observed daily over the observation period between treatments were analysed using a general linear mixed model. The model included BEP treatment as a predictor variable and hive ID as a random variable since hives were observed across multiple days. The distribution of the total number of foragers was log transformed in order to achieve normality. Differences in the proportion of pollen foragers between treatments in experiment 1 were tested using a binomial generalised linear mixed model using the same predictors as in the analysis of the total number of foragers.

For experiment 2, the total number of foragers was $\log$ transformed and analysed using a general linear model, with BEP treatment used as a predictor variable and hive ID set as a random factor. The proportion of pollen foragers was analysed with a binomial generalised linear model. Statistical analyses were conducted using $R$ and GraphPad Prism.

\section{RESULTS}

\subsection{Experiment 1: effect of BEP on the amount of capped brood}

BEP treatment had no effect on the amount of capped brood in the colonies after 3 weeks (unpaired $t$ test: $t=0.273, P=0.785, N=73$ ) or after 5 weeks (unpaired $t$ test: $t=0.862, P=$ $0.391, N=73$, Figure 1).

\subsubsection{Experiment 1: effect of BEP on foraging behaviour}

In colonies treated with BEP, there were significantly fewer foragers (generalised linear mixed model (GLMM), $t=-2.349$, degrees of freedom (d.f.) $=13, P=0.035$, Figure 2a) and a lower proportion of pollen foragers (binomial GLMM, $z=2.44$, d.f. $=1, P=0.014$, Figure 2b) than in untreated colonies.

\subsubsection{Experiment 2: effect of BEP on the amount of capped brood}

Three weeks of BEP treatment had no effect on the total amount of capped brood found in the colony (unpaired $t$ test: $t=1.320, P=0.192$, $N=56$, Figure $3 \mathrm{a}$ ). When the change in capped 


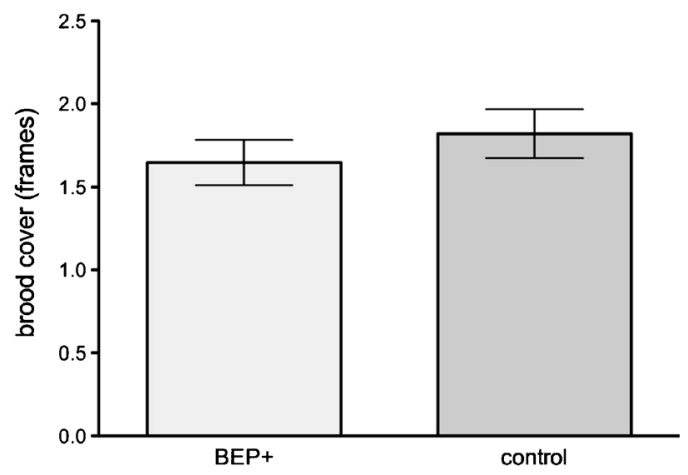

Figure 1. Mean ( \pm S.E.M.) number of brood frames covered with capped brood cells after 5 weeks of BEP treatment in experiment $1(N=73)$. BEP treatment had no effect on colony growth in this experiment

brood over the treatment period was examined (by taking the final brood cover from the colony frames and subtracting it from the initial brood cover), in both BEP treated and untreated colonies, there was a decline in brood area during this period. While this decline was less in BEP-treated colonies than in controls, this difference was not statistically significant (unpaired $t$ test: $t=1.969, P=0.054, N=56$, Figure 3b).

\subsubsection{Experiment 2: effect of BEP on foraging behaviour}

In the second experiment, BEP treatment had no effect on the total number of foragers observed (GLM, $t=2.056$, d.f. $=12, P=0.117$, Figure $4 \mathrm{a}$ ) and furthermore had no effect on the proportion of pollen foragers (binomial GLM, $z=-0.056$, d.f. $=1, P=0.956$, Figure $4 \mathrm{~b}$ ).

\section{DISCUSSION}

In this study we examined the effect of BEP treatment on brood cover and foraging behaviour in two experiments representing two contrasting conditions. In experiment 1, conducted early in the season, colonies were newly established from packages. In this experiment, BEP treatment had no effect on brood production (Figure 1) and decreased foraging activity (Figure 2a) as well as the proportion of pollen foragers (Figure 2b). Experiment 2 was conducted late in the season, in established colonies. Here, BEP had no effect on the absolute amount of capped brood present at the end of the experiment or on the change in brood cover over the treatment period (Figure 3). BEP treatment had no effect on
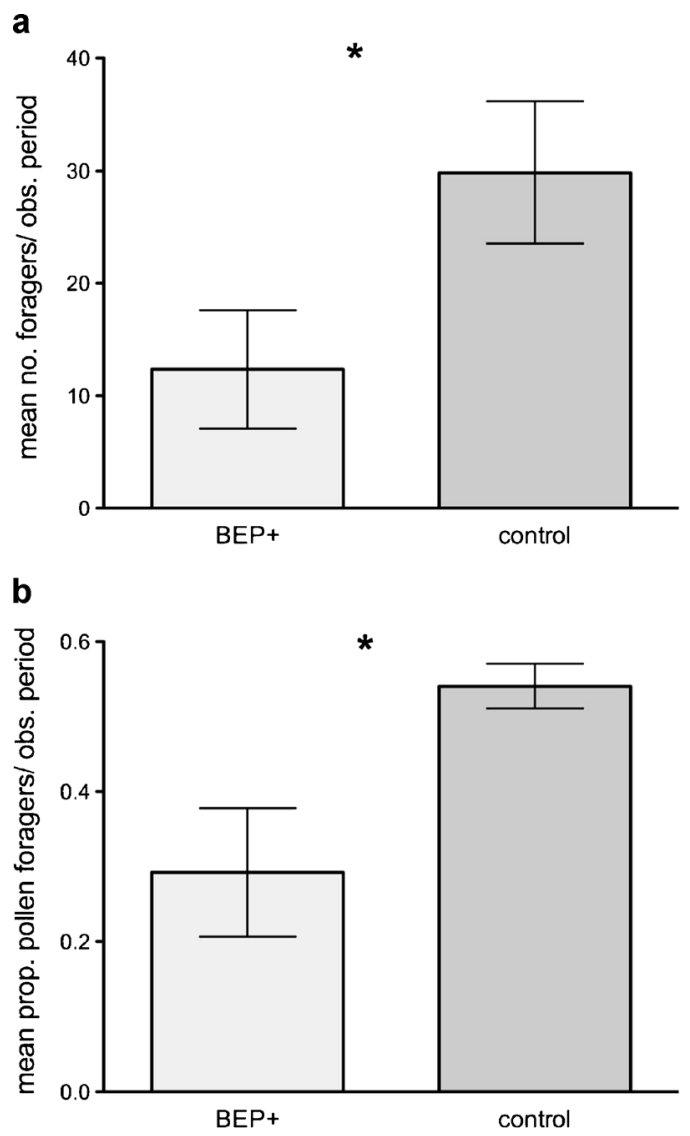

Figure 2. a Mean ( \pm S.E.M.) number of foragers in colonies treated with $\mathrm{BEP}(\mathrm{BEP}+)$ and without $\mathrm{BEP}$ (control) observed during experiment $1(N=15)$. BEP decreased overall foraging activity in treated colonies. b Mean ( \pm S.E.M.) proportion of pollen foragers in colonies treated with BEP (BEP+) and without BEP (control) observed during experiment 1. BEP decreased the proportion of pollen foragers in treated colonies. * indicates significant differences 
a

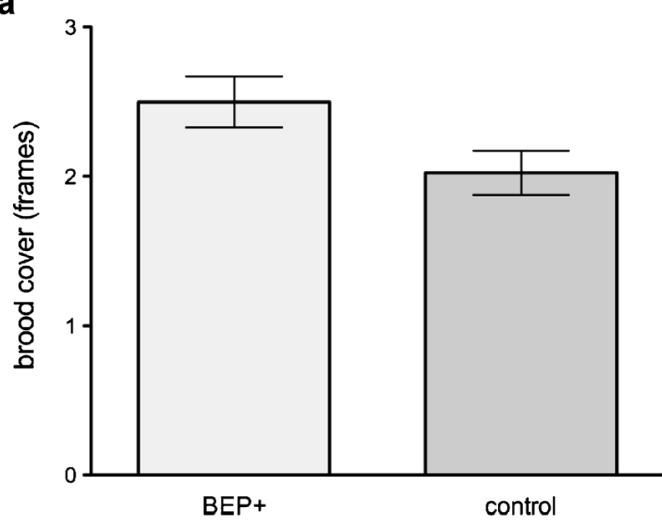

b

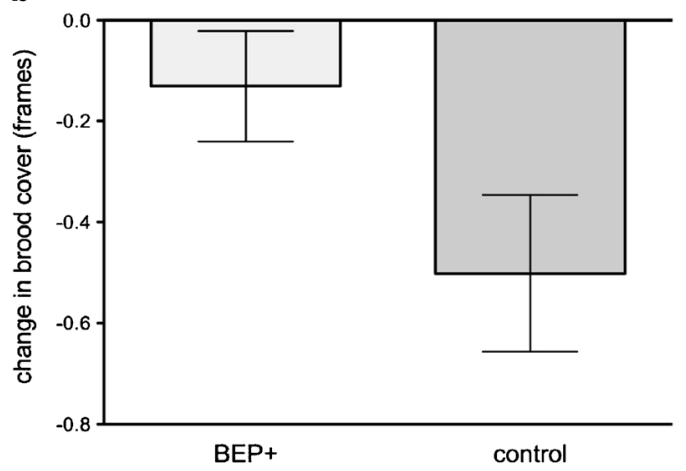

Figure 3. a Mean ( \pm S.E.M.) number of brood frames covered with capped brood cells after 3 weeks of BEP treatment in experiment $2(N=56)$. b Mean $( \pm$ S.E.M.) difference in brood cover (brood cover before treatment - brood cover after treatment) over the course of 21 days in experiment 2. BEP had no effect on brood area in treated colonies

foraging activity (Figure 4a) or on the proportion of pollen foragers (Figure 4b).

In experiment $1, \mathrm{BEP}$ treatment had no effect on brood cover. In colonies established from packages, the colony consists of a relatively small population of middle-aged bees. Evidence indicates that small colonies behave differently to large colonies, devoting all of their energetic resources to survival rather than growth (Rueppell et al. 2009). It is likely that added BEP cannot enhance colony growth in small colonies that are unable to allocate resources to growth.
Our results examining foraging in experiment 1 were unexpected. In highly controlled lab experiments, several studies have shown increases in overall foraging and pollen foraging in BEP-treated colonies (Pankiw et al. 1998; Pankiw and Page 2001; Pankiw 2007; Pankiw et al. 2008; Sagili and Pankiw 2009; Sagili et al. 2011). But in experiment 1 , we saw that BEP treatment decreased overall foraging and pollen foraging in colonies established from packages.
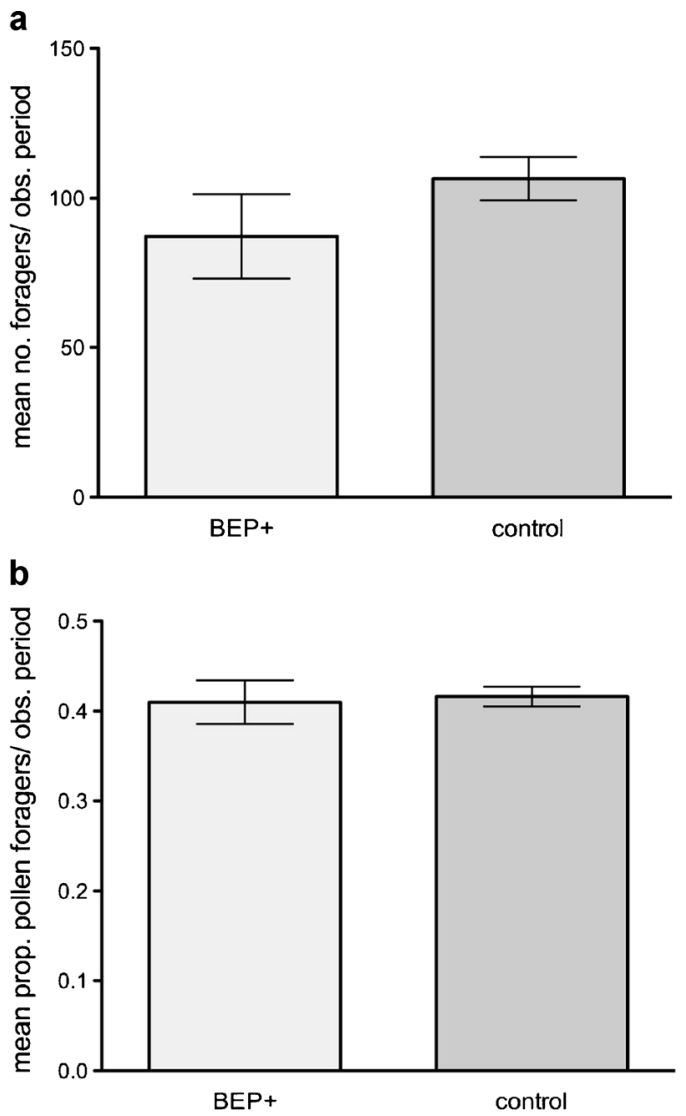

Figure 4. a Mean ( \pm S.E.M.) number of foragers in colonies treated with $\mathrm{BEP}(\mathrm{BEP}+)$ and without $\mathrm{BEP}$ (control) observed during experiment $2(N=14)$. BEP had no effect on foraging in treated colonies. b Mean $( \pm$ S.E.M.) proportion of pollen foragers in colonies treated with $\mathrm{BEP}(\mathrm{BEP}+)$ and without BEP (control) observed during experiment 1 . BEP had no effect on the proportion of pollen foragers observed in these colonies 
Some responses to BEP are highly dose dependent. For example, high doses of BEP have been shown to delay foraging in workers (Le Conte et al. 2001), whereas low doses accelerate it (Le Conte et al. 2001). It is possible that the BEP dose in SB is not optimised for small package colonies and may have triggered a delay in foraging onset in most bees resulting in reduced overall foraging activity. But we caution that this unexpected result needs independent verification.

In experiment 2, conducted on established colonies, BEP had no significant effect on the absolute amount of brood present at the end of the experiment. This is contrary to some previous studies. Sagili and Breece (2012) and Pankiw et al. (2011) (who used an SB prototype for BEP administration) found increased brood area in established colonies treated with BEP in the autumn. Moeri et al. (2011) treated established colonies in the early spring and also observed colony growth in colonies containing BEP. In our study any effect of BEP supplementation on brood production was small, relative to the observed variation in brood across our experimental colonies. This is similar to data reported by Lait et al. (2012), which also observed a trend to increased brood production in new colonies with BEP, but this was not statistically significant. Our data would suggest that there is no clear effect of BEP on brood production; however, considering all studies reported so far (Moeri et al. 2011; Lait et al. 2012; Sagili and Breece 2012), we suggest that BEP treatment has a greater effect on colony growth in established colonies than in package colonies.

When we treated colonies with BEP in experiment 2, foraging behaviour was not affected. When testing an SB prototype, Pankiw et al. (2011) found increased foraging activity and increased pollen foraging in treated colonies. Measured foraging activity is dependent on both the availability of resources in the environment as well as the motivation of bees to collect those resources. BEP would have no effect on foraging activity if there were no available nectar and pollen to collect, and fluctuations in these resources could obscure the measurable effects of BEP. The colonies in experiment 2 experienced a pollen dearth prior to the experiment and were moved to an area where pollen was abundant 2 weeks before we began observations. Colonies with experimentally lowered pollen stores enhanced their foraging effort significantly, both with existing pollen foragers increasing their collection rate and new pollen foragers entering the foraging force (Fewell and Winston 1992). It is possible that the colonies in our study were already foraging for pollen at maximum capacity to compensate for earlier pollen deprivation, and BEP treatment could not in this circumstance further increase pollen foraging. Further testing of BEP on established colonies will resolve the circumstances under which BEP might enhance foraging activity.

Our data caution how the behaviour of individual bees and colony growth trajectories are influenced by multiple factors simultaneously. Our data show that BEP treatments can change the behaviour of bees, but these can only translate into improved colony conditions if other factors are not limiting of colony performance.

\section{ACKNOWLEDGMENTS}

We thank Charles Péyvel for the use of his hives, his SuperBoost, his invaluable assistance in experimental set up and for providing lodging in the field. We thank Dave Flanagan for his beekeeping assistance. We also thank Rémi Padé, Yian Yian Dam, Flavia Massaro, Ian Tucker, Miya Warrington, Veronica Peralta, Phil Allen, Chris Weldon, and Dan Noble for assisting with observations and helping with bee marking. A final thank you is given to two anonymous reviewers who provided helpful suggestions for improving this manuscript. This work was supported by a Macquarie University Research Excellence Scholarship awarded to MP.

Les effets de la phéromone du couvain sur le comportement d'approvisionnement et le développement de la colonie dans des installations apicoles

Apis mellifera / ester / effet sur adultes / traitement / performance de la colonie 
Der Einfluss des Brutesterpheromons auf das Sammelverhalten und die Volksentwicklung in der praktischen Imkerei

\section{Brutesterpheromon / Apis mellifera / Sammeln / Volksentwicklung}

\section{REFERENCES}

Arnold, G., Le Conte, Y., Trouiller, J., Hervet, H., Chappe, B., Masson, C. (1994) Inhibition of worker honeybee ovaries development by a mixture of fatty acid esters from larvae. C. R. Acad. Sci. III 317(6), 511-515

Barron, A., Schulz, D., Robinson, G. (2002) Octopamine modulates responsiveness to foraging-related stimuli in honey bees (Apis mellifera). J. Comp. Physiol. A. 188(8), 603-610

Borden, J. (2011) Superboost: A Scientific Summary. Contech Enterprises Ltd, Canada.

Fewell, J.H., Winston, M.L. (1992) Colony state and regulation of pollen foraging in the honey bee, Apis mellifera L. Behav. Ecol. Sociobiol. 30(6), 387-393

Lait, C.G., Borden, J.H., Kovacs, E., Moeri, O.E., Campbell, M., Machial, C.M. (2012) Treatment with synthetic brood pheromone (SuperBoost) enhances honey production and improves overwintering survival of package honey bee (Hymenoptera: Apidae) colonies. J. Econ. Entomol. 105(2), 304-312

Le Conte, Y., Arnold, G., Trouiller, J., Masson, C., Chappe, B. (1990) Identification of a brood pheromone in honeybees. Naturwissenschaften 77(7), 334-336

Le Conte, Y., Mohammedi, A., Robinson, G. (2001) Primer effects of a brood pheromone on honeybee behavioural development. Proc. R. Soc. B. 268(1463), 163-168

Moeri, O.E., Lait, C.G., Kovacs, E., Borden, J.H., Campbell, M. (2011) SuperBoost ${ }^{\circledR}$ synthetic brood pheromone enhances spring build-up of overwintered honey bee colonies. J. Apic. Res. 50(4), 265-271

Mohammedi, A., Paris, A., Crauser, D., Le Conte, Y. (1998) Effect of aliphatic esters on ovary development of queenless bees (Apis mellifera L.). Naturwissenschaften 85(9), 455-458
Naumann, K., Winston, M.L. (1990) Effects of package production on temporal caste polyethism in the honey bee (Hymenoptera: Apidae). Ann. Entomol. Soc. Am. 83(2), 264-270

Pankiw, T. (2004) Brood pheromone regulates foraging activity of honey bees (Hymenoptera: Apidae). J. Econ. Entomol. 97(3), 748-751

Pankiw, T. (2007) Brood pheromone modulation of pollen forager turnaround time in the honey bee (Apis mellifera L.). J. Insect Behav. 20(2), 173-180

Pankiw, T., Page, R. (2001) Brood pheromone modulates honeybee (Apis mellifera L.) sucrose response thresholds. Behav. Ecol. Sociobiol. 49, 206-213

Pankiw, T., Page, R., Kim Fondrk, M. (1998) Brood pheromone stimulates pollen foraging in honey bees (Apis mellifera). Behav. Ecol. Sociobiol. 44(3), 193198

Pankiw, T., Roman, R., Sagili, R., Zhu-Salzman, K. (2004) Pheromone-modulated behavioral suites influence colony growth in the honey bee (Apis mellifera). Naturwissenschaften 91(12), 575-578

Pankiw, T., Sagili, R., Metz, B. (2008) Brood pheromone effects on colony protein supplement consumption and growth in the honey bee (Hymenoptera: Apidae) in a subtropical winter climate. J. Econ. Entomol. 101(6), 1749-1755

Pankiw, T., Birmingham, A.L., Lafontaine, J.P., Avelino, N., Borden, J.H. (2011) Stabilized synthetic brood pheromone delivered in a slow-release device enhances foraging and population size of honey bee, Apis mellifera, colonies. J. Apic. Res. 50(4), 257-264

Peters, L., Zhu-Salzman, K., Pankiw, T. (2010) Effect of primer pheromones and pollen diet on the food producing glands of worker honey bees (Apis mellifera L.). J. Insect Physiol. 56(2), 132-137

Rueppell, O., Kaftanouglu, O., Page, R.E. (2009) Honey bee (Apis mellifera) workers live longer in small than in large colonies. Exp. Geront. 44(6-7), 447-452

Sagili, R.R., Breece, C.R. (2012) Effects of brood pheromone (SuperBoost) on consumption of protein supplement and growth of honey bee (Hymenoptera: Apidae) colonies during fall in a northern temperate climate. J. Econ. Entomol. 105(4), 1134-1138

Sagili, R., Pankiw, T. (2009) Effects of brood pheromone modulated brood rearing behaviors on honey bee (Apis mellifera L.) colony growth. J. Insect Behav. 22(5), 339-349

Sagili, R., Pankiw, T., Metz, B. (2011) Division of labor associated with brood rearing in the honey bee: how does it translate to colony fitness? PLoS One 6(2), 1-7 